\title{
Competency, leadership and technology use by principals
}

\begin{abstract}
Principals have a major responsibility for initiating and implementing school change through the use of information and communications technology and can facilitate complex decisions to integrate it into learning, teaching and school administration. However, there is less information about the current status of ICT use by principals, their perceived competence in it, and their leadership style. This paper will report on these issues from an analysis of data gathered from a survey of secondary school principals in Tehran, Iran. The findings indicated that principals spent a few times a week working on their computers. Also, computer competence and transformational leadership contributed significantly to the level of computer use by principals. It was suggested that considerable ongoing professional development opportunities need to be provided for principals to fulfill their role as technology leader.
\end{abstract}

Keyword: Leadership, Information and Communication Technology, Secondary School Principals 